\title{
Editorial
}

\section{The Value of Identifying Major T Cell Epitopes of Clinically Important Allergens}

\author{
Winfried F. Pickl \\ Christian Doppler Laboratory for Immunomodulation and Institute of Immunology, Center for Pathophysiology, \\ Infectiology and Immunology, Medical University of Vienna, Vienna, Austria
}

Bahia grass is a subtropical grass species native to Argentina, Brazil, Paraguay and Uruguay, which has recently been introduced into the more temperate zones of the globe to grow in lawns or for agricultural purposes [1]. In temperate climate zones Paspalum notatum flowers and pollinates late into summer and can cause allergic symptoms during an extended period of time when compared to other grasses. In subtropical regions, it can be regarded as a perennial species.

The immunoglobulin $\mathrm{E}$ (IgE) response to the major/ group 1 Bahia grass pollen allergen, Pas $\mathrm{n} 1$, involves monospecific entities which react solely with Pas $n 1$, but also cross-reactive species, which bind to allergens of other grass species, e.g. Lol p 1 [Rye grass (Lolium perenne)]. The observed cross-reactivity is, however, not unexpected, given the high-degree of sequence identity of major pollen allergens of different grass species.

While specific immunotherapy of grass pollen allergy is an established and disease-modifying form of causative treatment [2], not all patients with this allergy are eligible for this treatment modality and side effects caused by intact allergens used for specific immunotherapy represent a non-negligible risk factor for adverse events. Intact, fulllength native allergen molecules have the potential to trigger IgE cross-linking on effector cells and to elicit immediate immune reactions, ranging from mild wheal and

\section{KARGER}

Fax +4161306 1234

E-Mail karger@karger.ch

www.karger.com
(C) 2012 S. Karger AG, Basel

$1018-2438 / 13 / 1601-0004 \$ 38.00 / 0$

Accessible online at:

www.karger.com/iaa flare reactions at the injection site to severe life-threatening anaphylactic reactions. Consequently, a multitude of strategies on how to interfere with the unintended allergenic activity of whole allergens has been developed in the past. These strategies include, but are not restricted to, the application of variant forms of major allergens such as chemically modified allergens, allergen fragments, hypoallergenic variants and linear peptide sequences of various lengths, which are unable to cross-link receptor-bound IgE and thus should reduce the risk for the sensitized patients.

The article by Etto et al. [3] published in a previous issue of International Archives of Allergy and Immunology provides a systematic identification of $\mathrm{T}$ cell-reactive peptides from Pas $n$ 1. Their objective was in fact the characterization of T-cell-reactive sequences within this allergen to be able to identify potentially useful peptide candidates, which could be used as potential therapeutics later on. Given the per definitionem low allergenicity/immunogenicity of such peptides, how, then, would future patients benefit from peptide identification and characterization?

Along these lines, Worm et al. [4] have very elegantly demonstrated that the T-cell-specific peptides of major allergens - when injected intradermally into allergic patients - have the potential to modify the allergic immune 
response by impacting on allergen-specific T lymphocyte function, provided that the peptides are short enough to not engage receptor-bound IgE. Such treatment, commonly referred to as 'peptide immunotherapy', has been shown to elicit inducible, allergen-specific regulatory $\mathrm{T}$ (Tr1) cells secreting the immunoregulatory cytokine interleukin (IL)-10 [5]. In addition, a substantial number of allergen-specific T cells might become driven into an anergic state and thus remain unresponsive during subsequent allergen challenges. Apart from these effects on T cell immunity, it is also believed that peptide immunotherapy might also have an impact on allergen-specific immunoglobulin levels with a slight propensity to foster the production of IgG4. At the moment, how this is achieved remains elusive. Given the fact that during peptide immunotherapy the allergen-peptides are the remedies themselves, they do not need to become adjuvanted; in fact, additional inflammatory stimuli are avoided in order to not activate allergen-specific effector T cells. Although representing an intriguing new concept, only few attempts to treat allergic diseases with peptide immunotherapy are reported as of today, among them allergies to cat hair, ragweed and bee venom. One of the reasons for the still limited use and application of peptide immunotherapy lies in the fact that detailed information about $\mathrm{T}$ cell epitopes of distinct major allergens is still scarce. In fact, the exact definition of immunodominant $\mathrm{T}$ cell epitopes of major allergens is a conditio sine qua non for future peptide immunotherapy trials, which will have to be based on the appropriate sequences.

The work by Etto et al. [3] provides important novel detail on Bahia grass, by identifying three immunodominant $T$ cell epitopes of Bahia grass pollen, namely Pas $n$ $1_{100-119}$, Pas n $1_{154-173}$ and Pas $n 1_{217-236}$ as well as 2 subdominant peptides, namely Pas $n 1_{127-146}$ and Pas $n$ $1_{190-209}$. Of significance, none of the immunodominant Pas $n 1$ peptides contain IgE-binding epitopes as revealed by dot-blot assays with patients' sera. This is very important information with regard to safety of use, which should allow for event-free application of peptides in future trials.

The immunodominant peptides are recognized by $83 \%$ of the analyzed $\mathrm{T}$ cell lines and are restricted by HLA-DR, with the additional recognition by HLA-DP of the intermediate epitope Pas n $1_{154-173}$. HLA-binding algorithms suggest that the peptides bind to 25,63 and $53 \%$, respectively, of the HLA-DR molecules that have been identified up till now. Given the considerable sequence similarity between group 1 grass pollen allergens, it was not entirely surprising that the $\mathrm{T}$ cell clones specific for the N-terminal and middle immunodominant peptide of Pas $\mathrm{n} 1$ also cross-reacted with the respective homologous peptides from Lol $\mathrm{p} 1$ and Cyn $\mathrm{d} 1$ [group 1 grass pollen allergen of Bermuda grass (Cynodon dactylon)]. Interestingly, no cross-reactivity was found for the homologues of the C-terminal immunodominant peptide Pas $n$ $1_{217-236}$.

The immunogenetic work-up of the allergic individuals from whom the $\mathrm{T}$ cell lines were generated suggests a high degree of binding degeneracy of the 3 immunodominant peptides; however, it also raises the question of whether or not a full coverage of the entire allergen can be achieved by using only 3 (or up to 5 , if the subdominant peptides are included) peptides in putative future therapy trials. From a conceptual point of view, a full coverage of all immunoreactive peptides might, however, not be required at all to still attain beneficial effects in a large group of genetically diverse individuals. In fact, evidence has been accumulated indicating that establishment of tolerance against one given peptide sequence out of a larger protein might lead to tolerance induction against neighboring sequences of that very protein, by a mechanism referred to as 'linked epitope suppression' [5]. Consequently, a restricted set of peptides covering the immunodominant molecules might suffice for effective treatment of a genetically diverse population.

Regardless of the precise future application modalities, the basic immunological work-up of the T cell immunoreactivity of Pas $n 1$ provided by Etto et al. [3] in this issue clearly illustrates the importance of mapping allergen-specific immune responses at the molecular level, in order to: (1) identify major and minor immunoreactive peptide sequences of an important allergen, (2) explore the immunogenetic background of the involved T cellular immune responses, (3) provide a basis for the establishment of altered peptide ligands as a tool to modify allergen-specific T cell responses, (4) address system-inherent safety issues, such as the serum IgE-reactivity/ nonreactivity of identified peptides and (5) provide basic information for building up human-relevant antigenpresenting cell/T cell systems as a reproducible in vitro toxicity test for future therapeutics [6, 7]. Finally, it is also a basis for engineering humanized in vivo models in which human-relevant restriction elements and corresponding human $\mathrm{T}$ cell receptors are coexpressed in the same individual (experimental animal) [Neunkirchner and Pickl, unpubl. data], which will facilitate the detailed investigation of the respective allergic disease in a living organism under experimental conditions.

Int Arch Allergy Immunol 2013;160:4-6 


\section{References}

$>1$ Hensel AE Jr, Griffith RC: Clinical experiences with Paspalum notatum (Bahia grass): a new grass antigen. South Med J 1972;65: 690-693.

$>2$ Durham SR, Walker SM, Varga EM, Jacobson MR, O’Brien F, Noble W, Till SJ, Hamid QA, Nouri-Aria KT: Long-term clinical efficacy of grass-pollen immunotherapy. $\mathrm{N}$ Engl J Med 1999;341:468-475.

3 Etto T, de Boer C, Prickett S, Gardner LM, Voskamp A, Davies JM, O’Hehir RE, Rolland JM: Unique and cross-reactive $\mathrm{T}$ cell epitope peptides of the major Bahia grass pollen allergen, Pas n 1. Int Arch Allergy Immunol 2012;159:355-366.
4 Worm M, Lee HH, Kleine-Tebbe J, Hafner RP, Laidler P, Healey D, Buhot C, Verhoef A, Maillere B, Kay AB, Larche M: Development and preliminary clinical evaluation of a peptide immunotherapy vaccine for cat allergy. J Allergy Clin Immunol 2011;127:89-97.

5 Campbell JD, Buckland KF, McMillan SJ, Kearley J, Oldfield WL, Stern LJ, Gronlund $\mathrm{H}$, van Hage M, Reynolds CJ, Boyton RJ, Cobbold SP, Kay AB, Altmann DM, Lloyd CM, Larche M: Peptide immunotherapy in allergic asthma generates IL-10-dependent immunological tolerance associated with linked epitope suppression. J Exp Med 2009; 206:1535-1547.
6 Leb VM, Jahn-Schmid B, Schmetterer KG, Kueng HJ, Haiderer D, Neunkirchner A, Fischer GF, Nissler K, Hartl A, Thalhamer J, Bohle B, Seed B, Pickl WF: Molecular and functional analysis of the antigen receptor of Art v 1-specific helper T lymphocytes. J Allergy Clin Immunol 2008;121:64-71.

7 Neunkirchner A, Leb-Reichl VM, Schmetterer KG, Mutschlechner S, Kueng HJ, Haiderer D, Schuch K, Wallner M, Jahn-Schmid B, Bohle B, Pickl WF: Human TCR transgenic Bet v 1-specific Th1 cells suppress the effector function of Bet $\mathrm{v}$ 1-specific Th2 cells. J Immunol 2011;187:4077-4087. 